\title{
Comparing two randomized deep brain stimulation trials for Parkinson's disease
}

\author{
*Günther Deuschl, MD, PhD, ${ }^{1}$ Kenneth A. Follett, MD, PhD,,3 Ping Luo, PhD, ${ }^{4}$ Joern Rau, MSc, ${ }^{5}$ \\ Frances M. Weaver, PhD, ${ }^{6}$ Steffen Paschen, MD, ${ }^{1}$ Frank Steigerwald, MD, ${ }^{7}$ Lisa Tonder, MS, ${ }^{8}$ \\ Valerie Stoker, $\mathrm{MPH},{ }^{7}$ and Domenic J. Reda, $\mathrm{PhD}^{4}$
}

\begin{abstract}
1Department of Neurology, Universitätsklinikum Schleswig-Holstein, Kiel Campus, Christian-Albrechts-University Kiel, Germany; ${ }^{2}$ Division of Neurosurgery, University of Nebraska Medical Center; ${ }^{3}$ VA Medical Center, Omaha, Nebraska; ${ }^{4}$ Department of Veterans Affairs Cooperative Studies Program Coordinating Center, Edward Hines Jr. VA Hospital, Hines, Illinois; ${ }^{5}$ The Coordinating Center for Clinical Trials, Philipps University, Marburg, Germany; ${ }^{6}$ Center of Innovation for Complex Chronic Health Care, Edward Hines Jr. VA Hospital, Hines, Illinois; ' Department of Neurology, University Hospital and Julius-Maximilian-University, Wuerzburg, Germany; and ${ }^{8}$ Medtronic, Inc., Minneapolis, Minnesota
\end{abstract}

OBJECTIVE Several randomized studies have compared the effect of deep brain stimulation (DBS) of the subthalamic nucleus with the best medical treatment in large groups of patients. Important outcome measures differ between studies. Two such major studies, the life-quality study of the German Competence Network for Parkinson's disease (LQ study) and the US Veterans Affairs/National Institute of Neurological Disorders and Stroke trial (VA/NINDS trial), were compared here in order to understand their differences in outcomes.

METHODS Unless otherwise noted, analyses were based on those subjects in each study who received a DBS implant (LQ study 76 patients, VA/NINDS trial 140 patients) and who had data for the measurement under consideration (i.e., no imputations for missing data), referred to hereafter as the "as-treated completers" (LQ 69 patients, VA/NINDS 125 patients). Data were prepared and analyzed by biostatisticians at the US Department of Veterans Affairs Cooperative Studies Program Coordinating Center, the Coordinating Center for Clinical Trials Marburg, and Medtronic, under the direction of two authors (G.D. and K.A.F.). Data were extracted from the respective databases into SAS data sets and analyzed using SAS software. Analyses were based on the 6-month follow-up data from both studies because this was the endpoint for the LQ study.

RESULTS Pre-DBS baseline demographics differed significantly between the studies, including greater levodopa responsiveness (LDR) in the LQ study population than in the VA/NINDS group. After DBS, LQ subjects demonstrated greater improvement in motor function (Unified Parkinson's Disease Rating Scale, Motor Examination [UPDRS-III]), activities of daily living (ADLs), and complications of therapy. Medication reduction and improvements in life quality other than ADLs were not significantly different between LQ and VA/NINDS subjects. When the two populations were compared according to pre-DBS LDR, the "full responders" to levodopa ( $\geq 50 \%$ improvement on UPDRS-III with medication) in the two studies showed no significant difference in motor improvement with DBS (LQ $18.5 \pm 12.0$-point improvement on UPDRS-III vs VA/NINDS $17.7 \pm 15.6$-point improvement, $p=0.755)$. Among levodopa full responders, ADLs improved slightly more in the LQ group, but scores on other UPDRS subscales and the Parkinson's Disease Questionnaire-39 were not significantly different between the two studies.

CONCLUSIONS This comparison suggests that patient selection criteria, especially preoperative LDR, are the most important source of differences in motor outcomes and quality of life between the two studies.

https://thejns.org/doi/abs/10.3171/2018.12.JNS182042

KEYWORDS deep brain stimulation; Parkinson's disease; outcomes; functional neurosurgery

\footnotetext{
ABBREVIATIONS ADL = activity of daily living; DBS = deep brain stimulation; HY = Hoehn and Yahr; L-dopa = levodopa; LDR = levodopa responsiveness; LED = levodopa equivalent dose; LQ study = German Competence Network for Parkinson's disease study; PD = Parkinson's disease; PDQ-39 = 39-Item Parkinson's Disease Questionnaire; PDQ-SI = PDQ summary index; STN = subthalamic nucleus; UPDRS-II = Unified Parkinson's Disease Rating Scale, Activities of Daily Living; UPDRS-III = UPDRS Motor Examination; UPDRS-IV = UPDRS Complications of Therapy; VA/NINDS = Veterans Affairs/National Institute of Neurological Disorders and Stroke. SUBMITTED July 26, 2018. ACCEPTED December 18, 2018.
} INCLUDE WHEN CITING Published online April 5, 2019; DOI: 10.3171/2018.12.JNS182042.

* G.D. and K.A.F. contributed equally to this paper. 
$\mathrm{D}$ EEP brain stimulation (DBS) of the subthalamic nucleus (STN) is an established therapy for patients with Parkinson's disease (PD). Four large studies have compared STN DBS and medical treatment in a randomized design. ${ }^{2,5,18,19}$ Despite overall consistency with respect to significant improvement in major outcome parameters among the studies, the amount of improvement via STN DBS differed considerably. The US Veterans Affairs/National Institute of Neurological Disorders and Stroke (VA/NINDS) trial has been heavily criticized on the basis that improvement in PD symptoms via DBS was substantially less than reported in other studies (e.g., 25\% improvement on the Unified Parkinson's Disease Rating Scale, ${ }^{4}$ Motor Examination [UPDRS-III] in the VA/NINDS trial vs approximately 50\% in some other studies), ${ }^{10}$ but the reasons for the disparity in outcomes are unknown and have never been addressed. This is an important question regarding the reproducibility of biomedical research and the outcomes of DBS for PD, so we decided to compare two major trials that we were involved in, ${ }^{2,5}$ which showed substantial differences in the scores rating motor outcomes and for which raw data were available to further investigate this question. The two studies were one conducted by the German Competence Network for Parkinson's disease (LQ study), which showed $41 \%$ improvement on the UPDRS-III, and one conducted by the US Department of Veterans Affairs/NINDS (VA/NINDS study), which showed $25 \%$ improvement. The VA/NINDS trial also included a group of subjects who underwent DBS of the globus pallidus interna. The latter group was not included in the present comparative analysis.

This post hoc analysis of the complete STN DBS data of the LQ study and the STN DBS data of the VA/NINDS study was conducted to explore the effects of study design and population differences on study results based on analyses of raw and summary data from each trial.

\section{Methods}

Seventy-eight patients were randomized to STN DBS in the LQ study, ${ }^{1}$ and 147 were randomized to STN DBS in the VA/NINDS study. ${ }^{5,18}$ These groups are referred to here as the "whole population." Unless otherwise noted, analyses were based on those subjects in each study who received a DBS implant (LQ study 76 patients, VA/NINDS trial 140 patients) and who had data for the measurement under consideration (i.e., no imputations for missing data), referred to hereafter as the "as-treated completers" (LQ 69 patients, VA/NINDS 125 patients).

Data were prepared and analyzed by biostatisticians at the US Department of Veterans Affairs Cooperative Studies Program Coordinating Center, the Coordinating Center for Clinical Trials Marburg, and Medtronic, under the direction of two authors (G.D. and K.A.F.). Data were extracted from the respective databases into SAS data sets and analyzed using SAS software (SAS Institute Inc.). Analyses were based on the 6-month follow-up data from both studies because that period was the endpoint for the LQ study. Unless otherwise noted, all analyses were conducted on the as-treated completers, i.e., those subjects who underwent surgery and for whom data were available for the primary measure under consideration (UPDRS-III scores with stimulation and without medication). No imputations were made for missing data. Twosample t-tests were performed for continuous comparisons and chi-square or Fisher exact tests were conducted for categorical comparisons of the LQ study versus the VA/NINDS study. A $p$ value $\leq 0.05$ was considered statistically significant, and no adjustments were made for multiple comparisons. Correlation analyses were also conducted to identify differences between the two studies. Results are presented as the mean \pm standard deviation unless otherwise noted.

For many controlled DBS studies, levodopa responsiveness (LDR) is an inclusion or exclusion criterion as there is a relationship between LDR and response to stimulation. ${ }^{1}$ Two major European trials used LDR of $33 \%{ }^{2}$ or $50 \%,{ }^{15}$ respectively, as an inclusion criterion because LDR may improve diagnostic accuracy for PD at earlier disease stages. ${ }^{8}$ Therefore, we evaluated the impact of LDR by grouping our two study populations according to the result of the levodopa (L-dopa) challenge at baseline as measured by the UPDRS-III in the medication-off and medication-on states. Patients were classified in groups comparable to those in the two European trials: ${ }^{2,15}$ full responders $(\geq 50 \%$ improvement in symptoms with L-dopa), partial responders $(33 \%-49 \%$ improvement), or low responders $(<33 \%$ improvement). Comparison of the full responders and partial responders was only possible because the VA/NINDS trial did not specify a minimum LDR for enrollment, so the low responders in the VA/NINDS population had no comparable group in the LQ study.

Motor function based on motor diaries was compared in the two studies, but diary categories differed between the two studies. The LQ study included categories for off, partially mobile, mobile (on) without dyskinesia, mobile (on) with dyskinesia, and asleep. In contrast, the VA/ NINDS study did not include a partially-on category. Subjects in the VA/NINDS study who might have selected "partially on" as an option were required to select either "off" or "on." The impact of this, whether they tended to select one category more often than the other, cannot be determined, so we considered "off" time to be the most uniform measure of function between the two studies.

Calculation of the levodopa equivalent dose (LED) was as follows, taken from EARLYSTIM calculations: ${ }^{15} 100$ $\mathrm{mg}$ levodopa $=133 \mathrm{mg}$ controlled release levodopa $=10$ $\mathrm{mg}$ bromocriptine $=1 \mathrm{mg}$ pergolide, lisuride, or cabergoline $=5 \mathrm{mg}$ ropinirole $=1 \mathrm{mg}$ pramipexole $=20 \mathrm{mg}$ dihydroergocryptine $=75 \mathrm{mg}^{5,18}$ levodopa plus entacapone $=10 \mathrm{mg}$ apomorphine $=3.3 \mathrm{mg}$ rotigotine. When entacapone was used the levodopa (L-dopa) dose was multiplied by 1.33 , and when tolcapone was used the L-dopa dose was multiplied by $1.5 \cdot 3,17$

\section{Results}

\section{Motor Outcomes}

Whole Population Comparison

Baseline data and a modified CONSORT flowchart for this post hoc analysis of the whole population of the LQ and VA/NINDS studies are shown in Table 1 and Fig. 1, 
TABLE 1. Baseline characteristics of the two study populations (whole population)

\begin{tabular}{lccc}
\hline \multicolumn{1}{c}{ Variable } & LQ Study $(\mathrm{n}=78)$ & VA/NINDS Study $(\mathrm{n}=147)$ & $\mathrm{p} \mathrm{Value}^{*}$ \\
\hline Male sex & $50(64.1)$ & $116(78.9)$ & $0.016 \dagger$ \\
\hline Age in yrs & $60.5 \pm 7.4$ & $61.9 \pm 8.7$ & 0.236 \\
\hline Duration of L-dopa treatment in yrs & $13.0 \pm 5.8$ & $11.1 \pm 5.0$ & $0.012 \dagger$ \\
\hline Modified HY score, off meds & $1(1.3)$ & $15(10.2)$ & $0.002 \dagger$ \\
\hline 2 & $10(12.8)$ & $22(15.0)$ & \\
\hline 2.5 & $17(21.8)$ & $50(34.0)$ & $0.011 \dagger$ \\
\hline 3 & $40(51.3)$ & $41(27.9)$ & $0.042 \dagger$ \\
\hline 4 & $10(12.8)$ & $19(12.9)$ & $<0.001 \dagger$ \\
\hline 5 & $18.9 \pm 9.3$ & $22.6 \pm 11.0$ & 0.812 \\
\hline UPDRS-III, on meds & $48.0 \pm 12.3$ & $44.0 \pm 14.7$ & $0.003 \dagger$ \\
\hline UPDRS-III, off meds & $22.5 \pm 7.2$ & $19.0 \pm 6.1$ & $0.005 \dagger$ \\
\hline UPDRS-II, off meds & $8.9 \pm 4.0$ & $9.0 \pm 2.9$ & 0.830 \\
\hline UPDRS-IV, off meds & $1207.7 \pm 550.9$ & $1463.2 \pm 716.3$ & 0.543 \\
\hline LED $\$$ & $41.8 \pm 13.9$ & $46.9 \pm 12.6$ & $55.7 \pm 18.1$ \\
\hline PDQ-SI & $55.0 \pm 23.6$ & $5.9 \pm 2.7$ & \\
\hline PDQ-39 ADL & $6.2 \pm 3.6$ & & \\
\hline Diary off time in hrs per day & &
\end{tabular}

meds = medications; $n=$ number of patients.

Values expressed as the mean \pm standard deviation or frequency $(\%)$, unless indicated otherwise.

* $p$ values were calculated using a chi-square or Fisher exact test for male sex and HY score; all other $p$ values were calculated using t-tests. † Statistically significantly different $(p<0.05)$.

$\ddagger$ LED was re-calculated using a new formula defined in the text.

respectively. Compared to the VA/NINDS trial, the LQ study enrolled a greater percentage of females and its subjects had, on average, higher modified Hoehn and Yahr (HY) scores $^{6}$ and worse UPDRS-III off-medication and UPDRS Activities of Daily Living (UPDRS-II) scores, better quality of life (Parkinson's Disease Questionnaire-3913 [PDQ-39] summary index [PDQ-SI]) and UPDRS-III on-medication scores, lower LED, and longer duration of L-dopa therapy. The LQ subjects received $29.1 \%$ of their LED as dopamine agonist compared to $17.4 \%$ among the VA/NINDS subjects.

Two of the 78 subjects enrolled in the LQ study and 7 of the 147 enrolled in the VA/NINDS trial did not receive DBS implants (Fig. 1), so outcome comparisons between the two studies were conducted based on the subjects in each study who had received DBS implants and for whom primary outcome data were available (as-treated completers). Baseline differences between the as-treated completers populations of the two studies were similar to those of the whole study populations except that HY scores, which were different between the whole populations of the two studies, were not significantly different between the two total as-treated completers populations (Table 2).

At the 6-month (post-DBS) follow-up, statistically significant differences were present between the total astreated completers populations, favoring the LQ group for improvement in motor symptoms (UPDRS-III off and on medication; UPDRS Complications of Therapy [UPDRSIV]; motor diaries) and activities of daily living (ADLs; UPDRS-II and PDQ-39 ADL; Table 3).

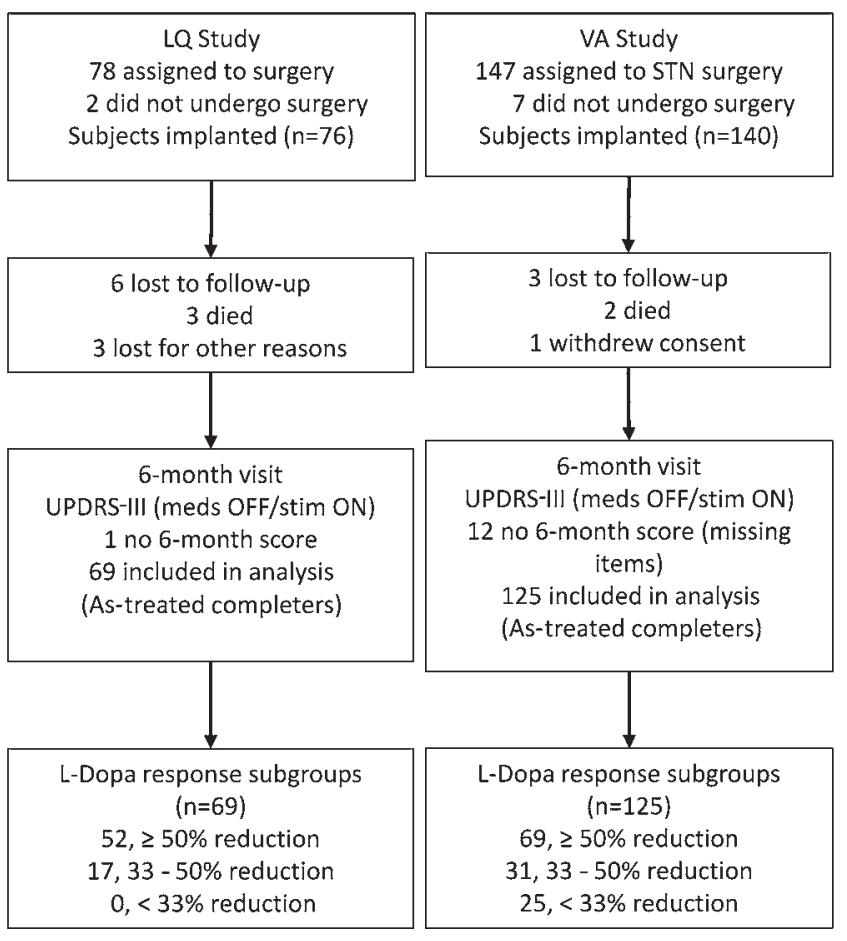

FIG. 1. Subject disposition. The L-dopa response subgroups refer to the percent improvement in the UPDRS-III on-medication score as compared with the off-medication score at baseline. meds = medications; stim $=$ stimulation . 


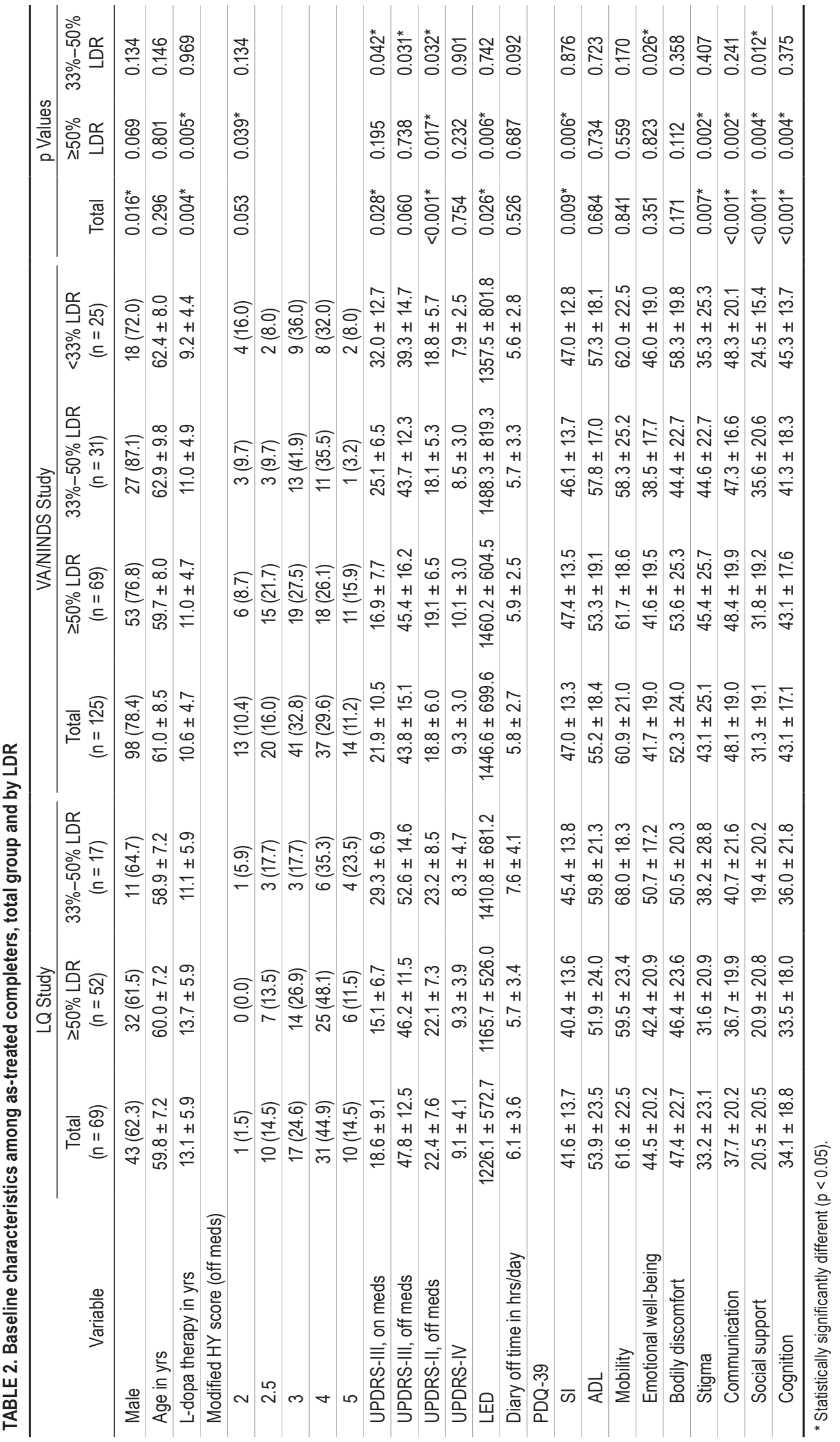




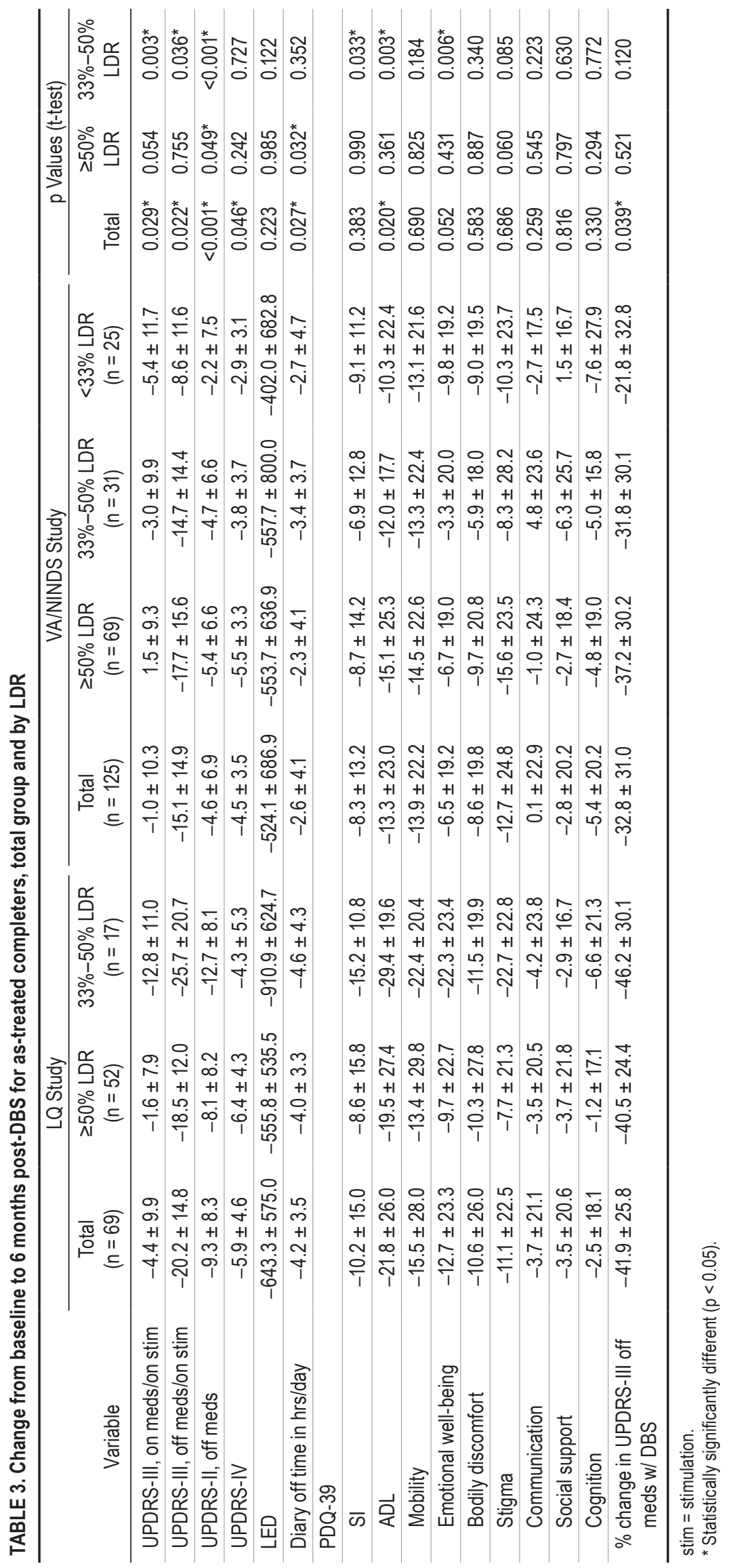




\section{L-Dopa Responder Subgroups}

At baseline, LQ subjects had, on average, worse UPDRS-III scores in the off-medication state and better UPDRS-III scores in the on-medication state than the VA/ NINDS subjects (Table 1), indicating greater preoperative LDR in the LQ population, which is consistent with study inclusion and exclusion criteria for pre-DBS LDR in the LQ study. Examination of demographics by LDR (Table 2) confirmed the greater LDR of the LQ study population: preoperatively, 52 subjects (75\%) were full responders and $17(25 \%)$ were partial responders (none were low responders because this subset was excluded from enrollment). In contrast, for the VA/NINDS study, 69 subjects (55\%) were full responders, 31 (25\%) were partial responders, and 25 (20\%) were low responders.

Further comparison of baseline demographics according to LDR (Table 2) showed similar motor function (UPDRS-III and motor diaries) between LQ and VA/ NINDS full responders. The following parameters were significantly different for full responders in the LQ study compared with those in the VA/NINDS study: worse HY scores, higher UPDRS-II scores, longer duration of L-dopa therapy, lower LED, and better quality of life (PDQSI). Full responders in the LQ and VA/NINDS studies had similar baseline LDR by definition. For the partial responders, UPDRS-III off and on medication and UPDRSII scores were higher for the LQ group. The full-responder populations, which were the most comparable subjects in the two studies, were analyzed in more detail.

For the full-responder groups, motor outcomes as measured by UPDRS-III on and off medication and UPDRS-IV were not statistically significantly different at the 6-month follow-up (Table 3). DBS in the off-medication state provided $18.5 \pm 12.0$-point improvement in the LQ group and $17.7 \pm 15.6$-point improvement in the VA/NINDS group $(\mathrm{p}=0.755 ; 40.5 \%$ and $37.2 \%$ improvement with DBS, respectively, $p=0.521$ ). The only statistically significant comparisons between the full-responder groups were the UPDRS-II $(p=0.049)$ and hours per day in the off state as measured by motor diaries $(p=0.032)$, favoring the LQ group.

\section{Activities of Daily Living}

Activities of daily living (UPDRS-II) differed significantly between the whole populations in the off-medication state at baseline (worse for LQ group; Table 1). Improvement was significantly smaller following DBS in the VA/NINDS as-treated completers population (Table 3). Among the L-dopa full responders, this difference between the LQ and VA/NINDS studies was reduced but was still statistically significant $(p=0.049)$, although the difference in UPDRS-II scores (2.7 points) for the full responders may not represent a clinically significant difference. $^{14}$

\section{Quality of Life}

The PDQ-SI baseline scores were lower (better) for the LQ group than the VA/NINDS group for the whole population (41.8 \pm 13.9 vs $46.9 \pm 12.6, p=0.005$; Table 1$)$, the as-treated completers $(41.6 \pm 13.7$ vs $47.0 \pm 13.3, p=0.009$;
Table 2), and the full responders $(40.4 \pm 13.6$ vs $47.4 \pm$ $13.5, p=0.006$; Table 2). But the change from baseline to 6 months was not significantly different between the studies for the as-treated completers populations and the fullresponder groups (as-treated completers: LQ $-10.2 \pm 15.0$ point change vs VA/NINDS $-8.3 \pm 13.2, \mathrm{p}=0.383$; full responders: LQ $-8.6 \pm 15.8$ vs VA/NINDS $-8.7 \pm 14.2$, p $=0.990 ;$ Table 3 ).

Subscores of the PDQ-39 differed at baseline for stigma, communication, social support, and cognition for the as-treated completers and the full-responder groups (Table 2). Following DBS, only improvement in the ADL subscale differed significantly between the LQ and VA/ NINDS studies, with the LQ as-treated completers (but not the full-responder population) demonstrating statistically significantly greater improvement on the ADL subscale than the VA/NINDS as-treated completers (LQ $-21.8 \pm 26.0$ point improvement vs VA/NINDS $-13.3 \pm$ 23.0 point improvement, $p=0.020$ ). In the populations of full responders, results were not statistically significant between the two study groups.

\section{Correlation Analyses}

Correlations were performed on these large data sets to determine whether response to treatment could be predicted from the baseline assessment. The severity of PD measured with the UPDRS-III in the off-medication condition at baseline had a strong correlation with the motor response to DBS in both studies (LQ: $r=-0.47, p<0.001$; VA/NINDS: $r=-0.50, p<0.001$; Fig. $2 \mathrm{~A}$ and B). The Ldopa response at baseline was a significant predictor for the VA/NINDS study ( $p=0.010$; Fig. 2D), but not for the LQ study ( $p=0.484$; Fig. 2 C), which did not include low responders and was a more homogeneous population.

\section{Discussion}

Two major randomized clinical trials of STN DBS for the treatment of PD were available for analysis of the underlying sources of differences in outcomes. The LQ study reported greater improvement with DBS (41\%) than was reported in the VA/NINDS study (25\%). We undertook a comparison of these two major studies to explore the effects of study design and population differences on outcomes. We have shown that differences in the two study populations and, in particular, LDR account for the variance in outcomes between these studies. Our analyses confirmed statistically significant differences between the study populations at baseline. Disease severity as measured by UPDRS-III was greater in the LQ group, and we showed that a higher (worse) UPDRS-III score correlates with a greater response to DBS. Similarly, the LQ study whole population was more responsive to L-dopa by virtue of the study inclusion criterion of at least $33 \%$ improvement on the UPDRS-III on medications, whereas the VA/ NINDS study required its participants to have L-dopa-responsive disease but did not set a minimum threshold of LDR for study enrollment-and we confirmed that LDR is an important determinant of response to DBS. Most importantly, motor outcomes of DBS did not differ between the LQ and VA/NINDS study groups when the comparison 
UPDRS-III (off med) at baseline vs, absolute change to 6 months (LQAs-treated completers, $n=69$ )

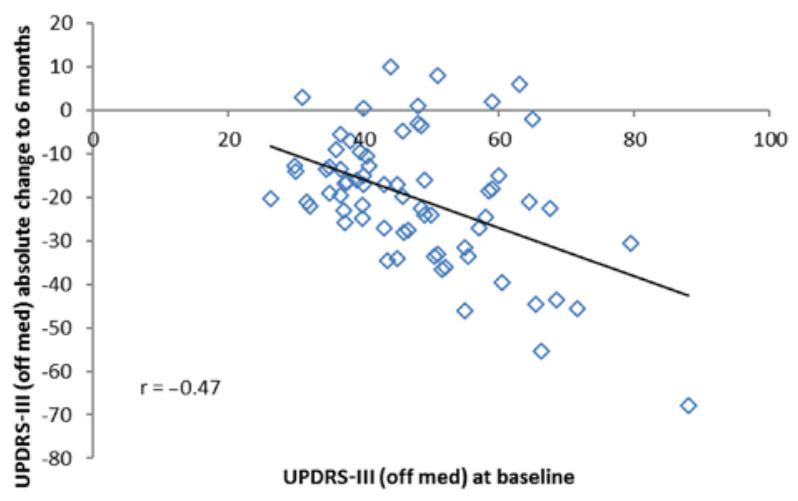

A

Note: Lower baseline values indicate better function.

\%L-dopa response at baseline vs. UPDRS-III (off med) $\%$ change to 6 months (LQ As-treated completers, $n=69$ )

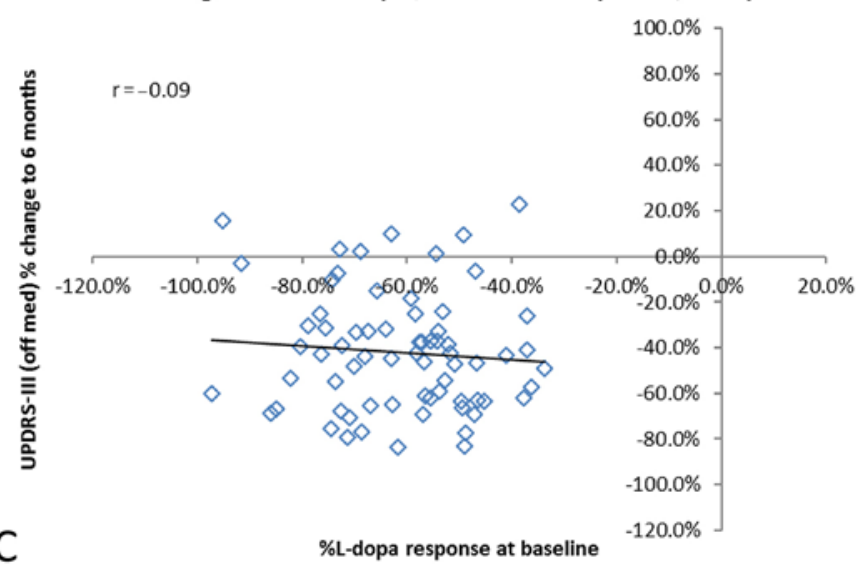

UPDRS-III (off med) at baseline vs. absolute change to 6 months (VA As-treated completers, $n=125$ )

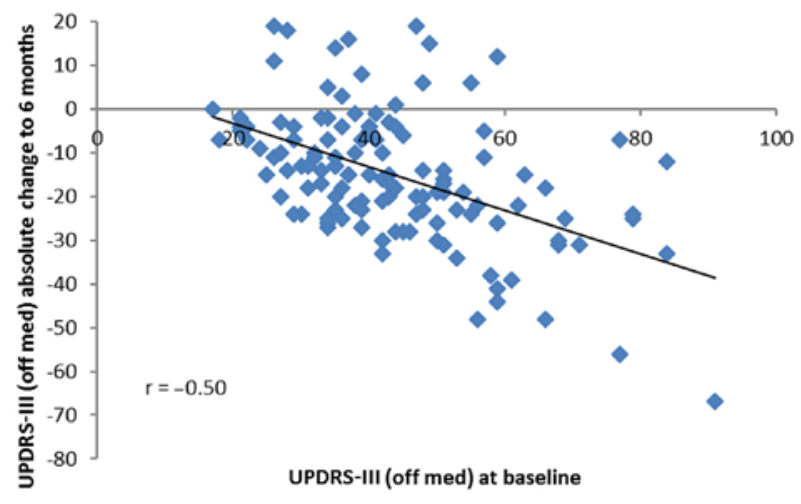

B

$\%$ L-dopa response at baseline vs. UPDRS-III (off med) $\%$ change to 6 months (VA As-treated completers, $n=125$ )

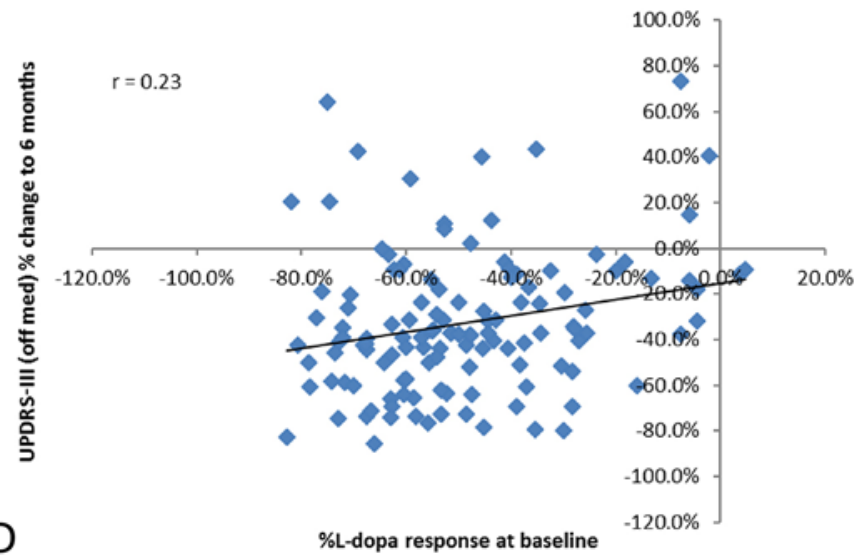

FIG. 2. Relationship of preoperative disease severity and LDR to DBS response in the as-treated completers groups. $A$ and $B$ : Baseline disease severity (UPDRS-III off medication) versus post-DBS absolute change in UPDRS-III (medication off/DBS on) at 6 months, which was found to be significant in both studies (LQ study, A; VA study, B). The difference in the slopes was not significant. C and D: Baseline LDR (\% change in UPDRS-III medication off to medication on) versus post-DBS \% change in UPDRS-III (medication off/stimulation on) at 6 months (LQ study, C; VA study, D). Figure is available in color online only.

was restricted to subjects with comparable baseline motor scores and LDR. The difference in post-DBS UPDRSIII off-medication/on-stimulation scores was reduced to only 0.8 points after adjusting for differences in the study populations, much less than the 2.7-point threshold for a clinically meaningful difference on the UPDRS-III. ${ }^{16}$ This analysis emphasizes again the importance of the preoperative selection criterion of L-dopa response and contributes to the understanding of the differences between two major clinical trials of DBS in patients with PD.

The main message of this paper is that differences in the cohorts in terms of L-dopa sensitivity may explain the poorer (criticized) study outcome of the VA/NINDS trial ${ }^{10}$ as compared with the LQ-study, thereby confirming sensitivity to L-dopa as an important predictor for improvement on the UPDRS-III with DBS. First, the absolute response of the UPDRS-III (off medication/on stimulation) to DBS depends significantly on the preoperative change with Ldopa, as has been shown elsewhere. ${ }^{1,9,11}$ This is most apparent in the VA/NINDS population, which included patients with a low L-dopa response, who were excluded in the LQ study. Second, we have shown that when similar populations (full responders with similar preoperative UPDRSIII scores off medication) are compared in both groups, motor improvement is similar and the large difference in terms of UPDRS-III improvement with DBS shrinks to an insignificant difference. Thus, the general concern expressed $^{12}$ about the VA/NINDS study having shown only a small improvement in mobility for the whole cohort is attributable to the enrollment of patients who had $<33 \%$ improvement with L-dopa. Our comparison supports the conclusion that the arbitrarily chosen lower border of $33 \%$ in the LQ study seems to give reasonable outcomes.

Outcomes of the two studies' full-responder groups, which had the most comparable pre-DBS characteristics, were not significantly different for any measure except ADLs (as measured by UPDRS-II) and hours per day in the off state as measured by motor diaries. The difference in ADLs was small (2.7 points, $\mathrm{p}=0.049$ ) and may not be clinically significant. ${ }^{14}$ Motor function as measured by 
diaries differed between the two studies, with LQ subjects reporting, on average, a 4-hour decrease in off time versus a 2.3-hour reduction for VA/NINDS subjects. This may reflect the studies' different protocols for completion of motor diaries. The LQ study included categories for off, partially mobile, mobile (on) without dyskinesia, mobile (on) with dyskinesia, and asleep. In contrast, the VA/ NINDS study did not include a partially-on category. The VA/NINDS subjects who might have chosen "partially on" if it were an option had to select "off" or "on"; they may have considered themselves more "off" than "on." Available data did not allow us to explore this further, so we cannot draw definitive conclusions regarding motor function as measured by diaries.

Factors influencing life quality and life-quality outcomes following DBS are more complicated. For the entire groups of as-treated completers in each study, the baseline PDQ-SI was worse in the VA/NINDS population than in the LQ population despite an opposite relation for disease severity as measured by the UPDRS-III off medication. At baseline for the full-responder groups, PDQ-SI was also worse in the VA/NINDS population than in the LQ population, although motor function (UPDRS-III) was not significantly different between the two. For the population of as-treated completers and for full responders, the worse PDQ-SI seems to be due mainly to less favorable values for the nonmotor domains of cognition, social support, communication, and stigma, whereas the domains of ADLs, mobility, emotional well-being, and bodily discomfort are similar for both populations. A variety of factors may account for differences in quality of life outcomes. For instance, patients in the US who obtain care within the VA healthcare system have poorer health-related quality of life than those who seek care outside the VA healthcare system. ${ }^{7}$ Whether poorer health-related quality of life is reflected similarly on the PDQ-39 for VA/NINDS subjects with PD is unknown. Factors such as differences in healthcare systems, access to care, and study participant comorbidities may also influence quality of life outcomes, but our data sets did not permit us to explore this possibility in greater detail.

Despite the differences in baseline life quality (PDQSI), improvement on the PDQ-39 was similar in both cohorts except for the ADL subscore, which was better in the LQ study when evaluating the as-treated completers populations. This difference was no longer seen when only the full responders were considered. This seems reasonable as the motor improvement was similar in the full responders.

\section{Conclusions}

In summary, this comparison has shown that the differences in the results of two major studies of STN DBS in advanced-PD patients are due to patient selection, particularly in terms of LDR. Results were not significantly different when evaluated for those subjects in both studies who demonstrated $50 \%$ or greater LDR. The inclusion criterion of L-dopa sensitivity above $33 \%$ seems to be important. Life quality measured with the PDQ-39 seems to depend on a more complex structure than pure disease severity measured with the UPDRS-III.

\section{Acknowledgments}

This study was supported by the Kompetenznetz Parkinson, TP 3 of the German Federal Ministry of Education and Research (BMBF), the Cooperative Studies Program of the Department of Veterans Affairs Office of Research and Development, the National Institute of Neurological Disorders and Stroke, and Medtronic. Dr. Deuschl was supported by the German Research Council (SFB 1261, B5). We thank Thomas Brionne, PhD, for support.

We acknowledge the members of the VA/NINDS CSP 468 Study Group. Chairpersons: Kenneth A. Follett, MD, PhD; Frances M. Weaver, PhD; Matthew Stern, MD. Chairpersons Office: Dolores Ippolito, MPH; Gatana Stoner, RN, CCRC. Hines VA Cooperative Studies Program Coordinating Center: Tammy Barnett, MA; Ken Bukowski, BS; Rosemarie DeNicolo; Kwan Hur, PhD; Joyce Jimenez; Ping Luo, PhD; Jan Motyka, BS; Domenic J. Reda, PhD; Theresa Simon, RN, BS; Bharat Thakkar, MS; Robert Woolson, JD, MS. Pharmacy Coordinating Center: Carol Fye, RPh, MS, CCRP; William Gagne; Crystal Harris, PharmD. National Institute of Neurological Disorders and Stroke: Jill Heemskerk, PhD; Claudia Moy, PhD; Paul Sheehy, PhD. Department of Veterans Affairs Cooperative Studies Program Central Office, VA Office of Research and Development: Timothy O'Leary, MD, PhD; Grant D. Huang, MPH, PhD. MAVERIC: Louis Fiore, MD; Robert Hall, MS. Health Economist: Kevin Stroupe, PhD. Executive Committee: Kim Burchiel, MD; Kenneth A. Follett, MD, PhD; Carol Fye, RPh, MS, CCRP; Crystal Harris, PharmD; Jill Heemskerk, PhD; Kwan Hur, PhD; William Koller, MD, PhD; William J. Marks Jr., MD, MS; Claudia Moy, PhD; Rajesh Pahwa, MD; Domenic J. Reda, $\mathrm{PhD}$; Johannes Rothlind, PhD; Oren Sagher, MD; Paul Sheehy, PhD; Matthew Stern, MD; Frances M. Weaver, PhD. Data Safety Monitoring Board: Roy Bakay, MD (Chairman); Rick Chappell, PhD; Robert Hart, MD; Robert Holloway Jr., MD, PhD; George McCabe, PhD; Margaret Schenkman, PhD; Jamal Taha, MD. Study Monitors: Julia Buckelew, CCRA; Carol Fye, RPh, MS, CCRP; Marilyn Garin; Sharon Matzek, CCRA; Donna Smith, CCRA. Site Investigators: Jeff Bronstein, MD, PhD; John Duda, MD; Penelope Hogarth, MD; Kathryn Holloway, MD; Stacy Horn, DO; Eugene C. Lai, MD, PhD; William J. Marks Jr., MD, MS; Ali Samii, MD. Site Coordinators: Farah Atassi, MD, MPH; Cecilia Bello, BSN; Lisette Bunting-Perry, RN, MSN, CCRC; Tina Conn, BSN; Alice Cugley, RN, NP; Nanette Eubank, RN, CCRP; Linda Fincher, RN, BSN; Romay Franks, BSN; Tammy Harris, MSN, RN, GNP; Mariann Haselman, RN; Susan Heath, RN, MS; Miriam Hirsch, MS, RN; Virginia Janovsky, RN, MN, MS; Elaine Lanier, RN, MS; Mary Lloyd, RN; Susan Loehner, BSN, MBA; Susan O'Connor, RN; Ligaya Ordonez, BSN; Heather Maccarone, RN, BSN; Kelli Massey-Makhoul, RN; Mary Matthews, RN; Elizabeth Meyn, BSN; Keiko Mimura, RN, MSN, GNP; Wes Morrow, MS, MMSc, PAC; Tammy Searles, RN; Jamye Valotta, BSN; Usha Vasthare, PhD; Monica Volz, RN, MS; Constance Ward, RN, MSN; Rebecca Warker, APRN; Heidi Watson, BSN; Pamela Willson, PhD. Neurologists: Mark Baron, MD; Matthew Brodsky, MD; Vincent Calabrese, MD; Gordon Campbell, ANP; Amy Colcher, MD; Emad Farag, MD; Eva Henry, MD; Jyh-Gong Hou, MD, PhD; Gail Kang, MD; Galit Kleiner-Fisman, MD; Jeff Kraakevik, MD; John Nutt, MD; Jill Ostrem, MD; Aliya Sarwar, MD; Indu Subramanian, MD; Zeba Vanek, MD. Neurosurgeons: Gordon Baltuch, MD, PhD; Kim Burchiel, MD; Antonio De Salles, MD, PhD; Jorge Eller, MD; Kathryn Holloway, MD; Paul Larson, MD; Richard Simpson, MD; Philip Starr, MD, PhD. Neuropsychologists: William Carne, PhD; Tom Erikson, PhD; Jeffrey Kreutzer, PhD; Mario Mendez, $\mathrm{MD}, \mathrm{PhD}$; Paul Moberg, PhD; John Ragland, PhD; Johannes Rothlind, PhD; Ronald Seel, PhD; Elizabeth Soety, PhD; Daniel Storzbach, PhD; Alexander Troster, PhD; Michele York, PhD. Neurophysiologist: Jurg Jaggi, PhD.

We acknowledge the members of the German LQ study (KNP, 
TP3). Carmen Schade-Brittinger; Paul Krack, MD, PhD; Jens Volkmann, MD, PhD; Helmut Schäfer, PhD; Kai Bötzel, MD, $\mathrm{PhD}$; Christine Daniels, MD; Angela Deutschländer, MD; Ulrich Dillmann, MD, PhD; Wilhelm Eisner, MD, PhD; Doreen Gruber, MD; Wolfgang Hamel, MD; Jan Herzog, MD; Rüdiger Hilker, MD, PhD; Stephan Klebe, MD; Manja Klo, MD; Jan Koy, MD; Martin Krause, MD; Andreas Kupsch, MD, PhD; Delia Lorenz, MD; Stefan Lorenzl, MD, PhD; H. Maximilian Mehdorn, MD, $\mathrm{PhD}$; Jean Richard Moringlane, $\mathrm{MD}, \mathrm{PhD}$; Wolfgang Oertel, MD, PhD; Marcus O. Pinsker, MD; Heinz Reichmann, MD, $\mathrm{PhD}$; Alexander Reus, MS; Gerd-Helge Schneider, MD; Alfons Schnitzler, MD, PhD; Ulrich Steude, MD, PhD; Volker Sturm, MD, PhD; Lars Timmermann, MD, PhD; Volker Tronnier, MD, PhD; Thomas Trottenberg, MD; Lars Wojtecki, MD; Elisabeth Wolf, MD; Werner Poewe, MD, PhD; and Jürgen Voges, MD, $\mathrm{PhD}$.

\section{References}

1. Charles PD, Van Blercom N, Krack P, Lee SL, Xie J, Besson $\mathrm{G}$, et al: Predictors of effective bilateral subthalamic nucleus stimulation for PD. Neurology 59:932-934, 2002

2. Deuschl G, Schade-Brittinger C, Krack P, Volkmann J, Schäfer H, Bötzel K, et al: A randomized trial of deep-brain stimulation for Parkinson's disease. N Engl J Med 355:896908, 2006

3. Deuschl G, Schüpbach M, Knudsen K, Pinsker MO, Cornu P, Rau J, et al: Stimulation of the subthalamic nucleus at an earlier disease stage of Parkinson's disease: concept and standards of the EARLYSTIM-study. Parkinsonism Relat Disord 19:56-61, 2013

4. Fahn S, Elton RL: Unified Parkinson's Disease Rating Scale, in Fahn S, Marsden CD, Goldstein M, et al (eds): Recent Developments in Parkinson's Disease. Florham Park, NJ: Macmillan Healthcare Information, 1987, Vol 2, pp 153-163

5. Follett KA, Weaver FM, Stern M, Hur K, Harris CL, Luo P, et al: Pallidal versus subthalamic deep-brain stimulation for Parkinson's disease. N Engl J Med 362:2077-2091, 2010

6. Goetz CG, Poewe W, Rascol O, Sampaio C, Stebbins GT, Counsell C, et al: Movement Disorder Society Task Force report on the Hoehn and Yahr staging scale: status and recommendations. Mov Disord 19:1020-1028, 2004

7. Howren MB, Cai X, Rosenthal G, Vander Weg MW: Associations of health-related quality of life with healthcare utilization status in Veterans. Appl Res Qual Life 7:83-92, 2012

8. Hughes AJ, Daniel SE, Kilford L, Lees AJ: Accuracy of clinical diagnosis of idiopathic Parkinson's disease: a clinicopathological study of 100 cases. J Neurol Neurosurg Psychiatry 55:181-184, 1992

9. Kleiner-Fisman G, Herzog J, Fisman DN, Tamma F, Lyons KE, Pahwa R, et al: Subthalamic nucleus deep brain stimulation: summary and meta-analysis of outcomes. Mov Disord 21 (Suppl 14):S290-S304, 2006

10. Krack P, Hariz MI: Parkinson disease: deep brain stimulation in Parkinson disease-what went wrong? Nat Rev Neurol 6:535-536, 2010

11. Limousin P, Krack P, Pollak P, Benazzouz A, Ardouin C, Hoffmann D, et al: Electrical stimulation of the subthalamic nucleus in advanced Parkinson's disease. N Engl J Med 339:1105-1111, 1998

12. Louis ED, Patel A: A trial of focused ultrasound thalamotomy for essential tremor. N Engl J Med 375:2203, 2016
13. Peto V, Jenkinson C, Fitzpatrick R, Greenhall R: The development and validation of a short measure of functioning and well being for individuals with Parkinson's disease. Qual Life Res 4:241-248, 1995

14. Schrag A, Sampaio C, Counsell N, Poewe W: Minimal clinically important change on the Unified Parkinson's Disease Rating Scale. Mov Disord 21:1200-1207, 2006

15. Schuepbach WM, Rau J, Knudsen K, Volkmann J, Krack P, Timmermann L, et al: Neurostimulation for Parkinson's disease with early motor complications. N Engl J Med 368:610-622, 2013

16. Shulman LM, Gruber-Baldini AL, Anderson KE, Fishman PS, Reich SG, Weiner WJ: The clinically important difference on the Unified Parkinson's Disease Rating Scale. Arch Neurol 67:64-70, 2010

17. Tomlinson CL, Stowe R, Patel S, Rick C, Gray R, Clarke CE: Systematic review of levodopa dose equivalency reporting in Parkinson's disease. Mov Disord 25:2649-2653, 2010

18. Weaver FM, Follett K, Stern M, Hur K, Harris C, Marks WJ $\mathrm{Jr}$, et al: Bilateral deep brain stimulation vs best medical therapy for patients with advanced Parkinson disease: a randomized controlled trial. JAMA 301:63-73, 2009

19. Williams A, Gill S, Varma T, Jenkinson C, Quinn N, Mitchell R, et al: Deep brain stimulation plus best medical therapy versus best medical therapy alone for advanced Parkinson's disease (PD SURG trial): a randomised, open-label trial. Lancet Neurol 9:581-591, 2010

\section{Disclosures}

Dr. Deuschl receives lecture fees from Boston Scientific and Novartis; is a consultant for Boston Scientific; has received royalties from Thieme publishers; is a government employee; and receives through his institution funding for his research from the German Research Council, the German Ministry of Education and Research, and Medtronic. Dr. Weaver has received grant funding from Medtronic to conduct a retrospective data study on long-term survival, healthcare use, and costs following deep brain stimulation for Parkinson's disease. Dr. Steigerwald reports grants and personal fees from Boston Scientific, grants from Medtronic, personal fees from St. Jude Medical/Abbott, and travel and educational grants from Grunenthal. Ms. Stoker and Ms. Tonder are employees of Medtronic.

\section{Author Contributions}

Conception and design: Follett, Deuschl, Rau, Tonder, Stoker, Reda. Acquisition of data: Paschen, Steigerwald. Analysis and interpretation of data: Follett, Deuschl, Luo, Rau, Weaver, Paschen, Steigerwald, Tonder, Reda. Drafting the article: Follett, Deuschl, Rau. Critically revising the article: Follett, Deuschl, Rau, Paschen, Steigerwald. Reviewed submitted version of manuscript: all authors. Approved the final version of the manuscript on behalf of all authors: Follett. Statistical analysis: Luo, Rau, Tonder. Administrative/technical/material support: Weaver, Stoker. Study supervision: Follett, Deuschl.

\section{Correspondence}

Kenneth A. Follett: University of Nebraska Medical Center, Omaha,NE.kfollett@unmc.edu. 